\title{
New Evidence from Assessing the Tobin Tax Effects on Exchange Stability and Trade
}

\author{
Dr. Said Jaouadi \\ Dept. of Finance and Banking, Jazan University \\ PO Box 114, Jazan, KSA \\ Tel: 966-7321-4436Ｅ-mail: said.economie@gmail.com
}

Received: June 28, 2013 Accepted: July 17, 2013

doi:10.5296/ber.v3i2.3929 URL: http://dx.doi.org/10.5296/ber.v3i2.3929

\begin{abstract}
The paper attempted to find out the economic effects of setting up a tax on currency transactions. Professor James Tobin was the first to propose the particular taxation to reduce the exchange volatility. Many authors interested by the Tobin tax topic, raised many statements against implementing such tax, they argued that it should tend to raise the fluctuations of exchanges rates, and in return, finish by harming the international trade.

In the empirical investigation of the paper, we carried out an econometric modeling focused on data about exchange rate volatility, international trade. To explore the effects of the Tobin tax on exchange volatility and international trade, we calculated the currency transactions costs according to a new methodology, covering the period 1990 - 2011, and finding out the effects of the taxation on the exchange market of these countries: United Kingdom, Japan and Germany.

The empirical investigation underlines two major findings, which allow us to reinforce establishing the tax on currency transactions, proposed by Professor James Tobin. The model puts emphasis on the decreasing effect of the Tobin tax on exchange volatility, it enabled us to infer that the currency taxation is contributing to improve the exchange rates stability. According to the estimation findings, the currency tax has positive impact on foreign trade, this evidence authorized us to denote that the Tobin tax tends to promote international trade transactions.
\end{abstract}

Keywords: Tobin tax, Speculation, Trade volume, Volatility, Transactions costs, Foreign currency tax, Exchange market, Foreign exchange. 


\section{Introduction}

In 1972, Professor James Tobin suggested in conference at Princeton to set up a tax equal to $1 \%$ on every currency transaction. For the author, applying tax on exchange market will have the same impact of throwing sand in the wheels of international finance, to reduce the speculation and in return the exchange market volatility.

In recent years, the Tobin tax topics were widely broached as critical question in international debates, imposing a tax on currency transactions should generate several benefits. The proposal of James Tobin was primarily targeting to reinforce the exchange markets stability. Although, during the last few years, many NGO contributed to diffuse the Tobin tax principle in the media and hereby, they facilitated the advertisement for the topic and created widespread for the tax proposal in international meetings. The prime interesting output of the Tobin tax project relies on the huge revenues generated from the taxation, which should help poor countries in eradicating poverty, according to theses NGO.

The Tobin tax becomes the prime issue of the bulk of debates in economic reviews and academic journals, because of its positive economic effects cited above. The focus of the international comunityon the Tobin tax issue made the Tobin proposal a pivotal question to fight poverty in developing countries, like promoted by several NGO.

\section{Literature review}

In economic theory, carrying out a tax on currency transactions seems a difficult task without agreement of the bulk of the developed countries. Therefore, many authors elaborated other variants of the Tobin tax. The preliminary assessment of their theoretical development were encouraging to establish such tax.

\subsection{The new Variants of Tobin Tax}

In fact, to apply a tax on currency transactions, we pointed out several difficulties that thwart implementation such taxation. Many authors contributed to develop flexible forms of the Tobin tax and to find solutions to some obstacles that could make the overwhelming Tobin tax project impossible to set up.

\subsubsection{The Variant of Spahn}

According to Spahn (1995), carrying out a tax on currency transactions could face several problems to come through, the author argued that: "analysis has shown that the Tobin tax as originally proposed is not viable and should be laid aside for good."

For Spahn, the major obstacle thwarting the Tobin tax project, remains in the distinction between normal liquidity and speculative trading in exchange market, the author stresses ${ }^{1}$ : "It is virtually impossible to distinguish between normal liquidity trading and speculative noise trading." In the sum, the author puts emphasis on carrying out a tax on currency transactions could be harmful with high rate and ineffective with low rate.

\footnotetext{
${ }^{1}$ Spahn, P. B. 1995. "International financial flows and transactions taxes: Survey and options." IMF working paper
} $\mathrm{WP} / 95 / 60$. 


\section{MInstitute Macrothink $^{\text {Int }}$}

Business and Economic Research

To avoid this problem, Spahn proposed to impose a tax on currency transactions with double items: low fix rate for normal currency transactions, and high variable rate solely applied in period of speculative noise trading.

\subsubsection{The proposal of Eichengreen et al}

According to Eichengreen et $\mathrm{al}^{2}$, exchange volatility is the direct result of speculative transactions in currency market, the authors attributed crucial role for banks to reduce the speculative trading volume. They suggested that banks should make special deposits without interest returns on the monetary authorities, the amount of deposit will depend on the volume of exchange transactions of short run.

With the new financial rule advanced by Eichengreen et al, it should virtually eliminate the speculative transactions on the currency market.

\subsubsection{The variant of Schmidt}

According to Schmidt, the Tobin taxation is a partial solution to avoid international financial crises, through limiting speculative transactions on currency markets.

The author argued that currency markets are decentralized, unregulated and moving, so any country attempting to apply the Tobin tax, will push the transactions of its currency to be made on offshore markets.

To thwart this weakness, the author suggested the importance of establishing the taxation on major developed countries, to avoid concurrence among countries and the tax revenues should be retrieved on the place of the currency transaction.

\subsection{The Tobin Tax and its Effect on Currency Volatility}

In economic literature, there are many theoretical essays founded to explore the relationship between taxing the currency transactions and the exchange volatility.

Introducing these theoretical developments remains quite important to illustrate the importance of this taxation in the international finance, we can sum up the effects of implementing the Tobin tax into two major statements:

\subsubsection{Stabilizing the Speculators Expectations}

It seems crucial to describe the stabilizer effect provided by implementing the Tobin tax, because, it should eliminate the opportunities to generate profits from speculative trading, through the deviations registered in the exchange rates market.

The stabilizer effect becomes more effective when the tax value is high, so we can argue that affecting the speculators expectations has major role to alter the decisions of noise trading on the currency market.

Reducing the speculator activities on currency markets should decrease the possibility of ${ }^{2}$ Eichengreen B., Wyplosz C. and Tobin J. 1993. "Two cases of sand in the wheels of international finance", Economic
journal, volume 13 . 
currency crisis creation, and avoid the crisis contagion effects among countries. The speculators plaid guilty in many papers for the advent of several crises. According to Taketa (2003): "it is quite important to investigate how such speculators can affect the market during contagious currency crisis."

\subsubsection{The Negative Impact on the Currency Market Liquidity:}

Fixing the amount of the tax on currency transactions should reduce the liquidity in the currency market and in return, it could harm the market efficiency. The lack of liquidity due to the Tobin taxation could arise preliminary fluctuations, and finish by increasing the currency volatility.

In several surveys, some authors stressed that there is no link between liquidity of currency market and the stability of exchange rates. Because of the simple reason that the rise of liquidity in the currency market in recent years, did not reduced the number of financial crises. According to (Bernardos, 2009) ${ }^{3}$ : "the creation of the first real estate bubble was mainly driven by great liquidity at global scale between 2001 and 2005."

\subsubsection{Assumptions}

Setting up a tax on currency transactions should arise directly the currency transactions costs. So, finding out the effect of these costs on exchange volatility and international trade, allows us to examine the effect of Tobin tax on volatility and foreign trade.

\section{Empirical Evidence}

\subsection{The Aliber Model}

The examination of the effects of the Tobin taxation on currency market was primarily concerned through many papers and surveys, many authors attempted to explore the real impact of the taxation on exchange volatility and international trade.

\subsubsection{The Model Presentation}

In 2001, Aliber et $\mathrm{al}^{4}$ carried out an empirical model to analyze the effect of a tax on currency transactions on the exchange volatility and the international trade. The authors put forward their model according to the following introduction:

$$
\begin{gathered}
\text { Volatility }_{t}=\propto \text { Cost }_{t}+\beta \text { Volatility }_{t-1}+\varepsilon_{t} \\
\text { Trade }_{t}=\gamma \text { Cost }_{t}+\delta \text { Trade }_{t-1}+\epsilon_{t}
\end{gathered}
$$

Where $\epsilon_{t}$ and $\varepsilon_{t}$ are error terms. Volatility represents the difference of exchange rate between two years.

\footnotetext{
${ }^{3}$ Bernardos G. 2009. "The rise and fall of the first global real estate bubble”, paradigmes issue n², June 2009, p99 - p106. ${ }^{4}$ Aliber R. Z., Bhagwan C. and Yan S. 2001. "Some evidence that a Tobin tax on foreign exchange transactions may increase volatility”, European Finance Review, 7, pp. 481-510, 2003.
} 
The variable "Cost" makes up the cost of currency transactions in the exchange market, the examination of its impact, thoroughly points up the effect of Tobin tax, due to the relevant positive relationship between the taxation and the transactions costs.

For the variable "Trade", it makes up the volume of transactions of futures, the variable indicates the number of long term transactions in the currency market, and in return, it reflects the volume of transactions of international trade. The sample of the empirical investigation conducted by Aliber et al (2001) includes 4 developing countries: USA, Japan, Germany and UK.

\subsubsection{The Methodology}

In economic literature, we assume that costs depend on the difference between the two terms of equilibrium in the market. Therefore, there is margin between supply and demand, which makes up the transaction costs of the market.

For Aliber et al, the currency market is considered in equilibrium if we reach the equality of the terms of the arbitration operation, following the presentation below:

$$
F_{t}=S_{t} \frac{(1+i)}{(1+i s)}
$$

Where: $i$ and $i^{*}$ are the domestic and the international interest rate.

$\mathrm{F}$ is the exchange rate future and $\mathrm{S}$ is the exchange rate spot.

Making the logarithm of (3), it provides

$$
\ln F(\tau, T)-\ln S(\tau, T)=i(\tau, T)-i^{*}(\tau, T)
$$

Making the difference between two periods T1 and T2, it gives

$$
\ln F(\tau, T 2)-\ln F(\tau, T 1) \approx i(\tau, T 1, T 2)-i^{*}(\tau, T 1, T 2)
$$

We can sum up the relation in

$$
p(T) \approx \Delta(T)
$$

We finish by finding

$$
D(T) \approx \Delta(T)-p(T)
$$

For the authors, the difference between the two terms of the equation, represents the cost of currency transactions on the market.

Therefore, the authors make the covariance of the difference between the two terms of the equality (7), using the following formula: 


$$
\operatorname{Cost}=\sqrt{-\frac{1}{2} \operatorname{Cov}(D t)}
$$

\subsection{The New Approach}

In this paper, we used another approach to calculate the costs of currency transactions. We considered another equilibrium condition, particularly distinct than the relationship adopted by Aliber et al (2001) focused on the arbitration operation, between the future rate and spot rate.

\subsubsection{The Methodology}

In the current paper, we conducted our empirical investigation focusing on the equality of Fisher. The latter resumed the equilibrium relationship between the real interest rates between the country and international interest rate. According to Fisher, countries using their production factors intensively, have the same development, in return we should finish by getting equality of their real interest rates.

The Fisher equality of real interest rates among countries is made up as following

$$
\mathrm{i}_{\mathrm{D}}=\mathrm{i}^{*}
$$

Where $i_{D}$ the domestic real interest rate and $i^{*}$ the international real interest rate. The nominal returns of interest rates are roughly equal to the real interest rate minus the price level, which give

$$
\mathrm{I}_{\mathrm{D}}-\mathrm{P}_{\mathrm{D}}=\mathrm{I}^{*}-\mathrm{P}^{*}
$$

Where: $\mathrm{P}_{\mathrm{D}}$ the domestic price index, $\mathrm{P} *$ the international price index, $\mathrm{I}_{\mathrm{D}}$ the domestic nominal interest rate, and $\mathrm{I}^{*}$ the international nominal interest rate.

We Finished by founding:

$$
\mathrm{I}_{\mathrm{D}}-\mathrm{I}^{*}=\mathrm{P}_{\mathrm{D}}-\mathrm{P}^{*}
$$

We can sum up the Fisher relationship, as compensating the variation of nominal interest rate by variation in the price index.

From equation (11), we can calculate the costs of currency transactions from the value of the difference between the two terms of this equality, as done by Aliber et al (2001).

$$
D_{t} \cong \Delta P-\Delta I
$$

From the equation 12, we can determine the cost of currency transactions by calculating the covariance:

$$
\operatorname{Cost}=\sqrt{-\frac{1}{2} \operatorname{Cov}(D t)}
$$




\subsubsection{The Data}

In the current paper, we used data about the exchange rate to calculate volatility, and the real and nominal interest rates and the exports and imports as shares of GDP, as variable reflecting the international trade. We collected the data from the database of the World Bank, World Development Indicators 2013. The sample of the elaborated survey is covering the period 1990 -2011 . We estimated our model using the method of ordinal least squares (OLS), for panel of three developed countries: Japan, Germany and Great Britain.

\subsection{Comparing the Results of the Two Approaches}

The model estimation authorized us to explore the effect of Tobin tax on volatility and international trade. We put forward the results in table 1 and table 2, to compare between the two approaches of costs calculations.

Table 1 . The effect of the Tobin tax on the exchange rates volatility.

\begin{tabular}{|l|c|c|c|c|c|c|}
\hline & \multicolumn{3}{|c|}{ The results of Aliber et al } & \multicolumn{2}{c|}{ The results of the new approach } \\
\hline countries & Great Britain & Germany & Japan & Great Britain & Germany & Japan \\
\hline Constant & -- & -- & -- & -0.004 & 0.5 & -9.03 \\
& & & & $(-0.54)$ & $(2.63)$ & $(-0.84)$ \\
\hline Transactions costs & $12.1^{* *}$ & 2.76 & $16.8 * * *$ & $0.09 * *$ & $-0.36 * *$ & 6.77 \\
& $(2.24)$ & $(0.53)$ & $(3.25)$ & $(2.5)$ & $(-2.53)$ & $(0.68)$ \\
\hline Exchange volatility t-1 & $0.55^{* * *}$ & $0.46^{* * *}$ & $0.36^{* * *}$ & 0.2 & -0.14 & 0.23 \\
& $(10.94)$ & $(8.4)$ & $(6.24)$ & $(1)$ & $(-0.65)$ & $(0.87)$ \\
\hline $\mathrm{R}^{2}$ & $31 \%$ & $21.3 \%$ & $18.5 \%$ & $30.4 \%$ & $27.4 \%$ & $12.8 \%$ \\
\hline
\end{tabular}

For the results of the effect of setting up Tobin tax on the international trade, they are summarized in the Table 2.

Table 2. The effect of the Tobin tax on international trade.

\begin{tabular}{|c|c|c|c|c|c|c|}
\hline & \multicolumn{3}{|c|}{ The results of Aliber et al } & \multicolumn{3}{|c|}{ The result of the new approach } \\
\hline countries & United Kingdom & Germany & Japan & United Kingdom & Germany & Japan \\
\hline \multirow[t]{2}{*}{ Constant } & -- & -- & -- & -0.14 & $39.5 * *$ & -3.97 \\
\hline & & & & $(-0.1)$ & $(2.53)$ & $(-1.39)$ \\
\hline \multirow[t]{2}{*}{ Transactions costs } & $-1.27 * * *$ & $-1.86^{*}$ & $-2.44 * * *$ & 1.3 & $-27.4 * *$ & $4.83 *$ \\
\hline & $(-3.56)$ & $(-1.82)$ & $(-3.66)$ & $(0.97)$ & $(-2.41)$ & $(1.79)$ \\
\hline \multirow[t]{2}{*}{ Exchange volatility } & $0.11 * * *$ & $0.49^{* * *}$ & $0.371 * * *$ & 17.3 & -12.2 & 0.06 \\
\hline & $(3.55)$ & $(4.54)$ & $(5.19)$ & (1.17) & $(-0.79)$ & $(0.93)$ \\
\hline \multirow[t]{2}{*}{ International trade ${ }_{\mathrm{t}-1}$} & $0.78 * * *$ & $0.85^{* * *}$ & $0.78^{* * *}$ & -0.25 & -0.27 & -0.29 \\
\hline & $(23.31)$ & $(30.01)$ & $(22.46)$ & $(-1.13)$ & $(-1.09)$ & $(-1.25)$ \\
\hline $\mathrm{R}^{2}$ & $73.3 \%$ & $80.8 \%$ & $72.2 \%$ & $18.2 \%$ & $28.1 \%$ & $24.8 \%$ \\
\hline
\end{tabular}




\section{MlMacrothink}

Business and Economic Research

ISSN 2162-4860

2013, Vol. 3, No. 2

According to Aliber et al, it seems that establishing a tax on currency transactions tends to raise the exchange volatility and to reduce the international trade for countries applying this tax. These effects remain statistically significant at $5 \%$ at the most cases for the sample of the estimation. Therefore, the authors argued that applying the Tobin tax on currency markets has destabilizing effect by rising the exchange volatility for countries, and finish by harming the international trade value.

In table 1 , all the $\mathrm{R}^{2}$ of the models are weak, including the results of Aliber et al, therefore, the models elaborated did not explain the reality because of the sensitivity of the volatility concept. For which many econometric models and methods are developed, we can cite the examples of: ARCH, GARCH, EGARCH, FIGARCH...

Although, according to the new approach adopted to calculate the currency costs, we found that establishing tax on currency transactions tends to reduce the exchange rates volatility. So imposing the Tobin tax could potentially stabilize the fluctuations of the exchange rates in the market. The statement is consolidated by (Erturk, 2013) ${ }^{5}$, the author emphasizes: "the core issue remains the contention that a small transactions tax would stabilize international currency markets by reducing volatility."

According to the tables, with the new approach of cost calculation, we found that for Germany, the cost transactions tend to reduce the volatility of the exchange rate. This result allows us to infer that establishing the Tobin tax could contribute to reduce the fluctuations of the exchange rate, according to (Palley, 2003) ${ }^{6}$ : "the tax would reduce volatility, in turn reducing the volatility risk..."

For Japan, it seems that setting up a tax on currency transactions tends to raise the international trade. We could explain the result by focusing on the effect of the Tobin tax on the expectations of speculators, the tax contribute to reduce the opportunities to generate profits from fluctuations of the exchange rate among countries. The benefic effect of Tobin tax when targeting the international trade depends on the level of the tax compared to the costs supported by traders. (Dodd, 2003) ${ }^{7}$ highlights: "the Tobin tax is small relative to the lower cost advantages of trading in the US over countries and this small tax would not there overwhelm these cost advantages."

\section{Conclusion}

This paper finished by providing new evidences in favor of fixing the Tobin tax in the financial world economy. Through the empirical investigation, the survey call into question the evidences found by many authors about the rise of volatility of exchange rates related to applying tax on currency transactions and about harming the international trade.

The Tobin tax remains promoting project and its harmful effects identified in the paper of Aliber et al, remain limited after altering the methodology of currency costs calculations,

\footnotetext{
${ }^{5}$ Erturk K. A. 2013. "On the Tobin tax”, Department of economics, University of Utah.

${ }^{6}$ Palley T. I. 2003. « the economic case of the Tobin tax », debating the Tobin tax, new rules for Global finance, Washington DC.

${ }^{7}$ Dodd R. 2003. « Lessons for Tobin tax advocates: the politics of policy and the economics market micro-structure », Derivatives study center.
} 
which represent the major empirical effort exerted in this paper.

The current paper attempted to sum up the effects of posing a Tobin tax in economic literature and provided new findings. The last should consolidate adopting such tax, because it could reduce volatility of exchange and improve the transactions of international trade. Primarily, many countries like Chili and Malaysia begun establishing variant to this tax in their exchange market and they reached significant economic effects, in favor of reinforcing the financial market stability and the international trade.

The results provided by this paper lead to infer that the Tobin tax could be an effective tool to reduce the exchange rates volatility and to promote the international trade. Given the threats of exchange instability, it seems reasonable to reinforce taxation on currency transactions, to promote exchange operations of international trade and to avoid the consequences of financial crises.

Eventually, the current paper is contributing to rehabilitate the Tobin tax proposal and to reinforce the hope to establish it. Recently, many NGO are encouraging the currency taxation. The economic effects of the tax argued by Professor James Tobin are not the major motivation of many international organizations. But, the huge volume of tax revenues has seduced many authors and NGO, it could serve to eradicate poverty in developing countries.

\section{References}

Aliber R. Z., Bhagwan C. and Yan S. (2001). Some evidence that a Tobin tax on foreign exchange transactions may increase volatility, European Finance Review, 7, 481-510, 2003.

Bernardos G. (2009). The rise and fall of the first global real estate bubble, paradigmes issue $n^{\circ} 2$, June 2009, 99-106.

Eichengreen B., Wyplosz C., \& Tobin J. (1993). Two cases of sand in the wheels of international finance, Economic journal, volume 13.

Erturk K. A. (2013). On the Tobin tax, Department of economics, University of Utah.

Frenkel J. (1977). Transactions costs and interest arbitrage: tranquil versus turbulent periods, journal of political economy, vol 85.

Palley T. I. (2003). The economic case of the Tobin tax », debating the Tobin tax, new rules for Global finance, Washington DC.

Riggs A. R., \& Velk T. (1999). The Tobin tax: a bad idea whose time has passed, Policy options.

Rodney S. (1999). A feasible foreign exchange transactions tax, Research Associate The North South Institute.

Rodney S. (2000). Is the Tobin tax practicable?, international development research center government of Canada, June 2000.

Shi K. (2008). Entry cost, Tobin tax, and noise trading in the foreign exchange market, Hong 
Kong University of science and technology, Simon Fraser University.

Singh J., \& Yadav P. (2011). Tobin tax and its applicability in India, international journal of multidisciplinary research, vol.1 issue 7.

Spahn P. B. (1996). La taxe Tobin et la stabilité des taux des changes, FMI, Finance et Développement.

Spahn, P. B. (1995). International financial flows and transactions taxes: Survey and options. IMF workingpaper WP/95/60.

Stotsky J. (1996). Pourquoi une taxe Tobin double est vouée à l'échec ? Finance \& Développement, Juin 1996.

Taketa K. (2003). A large speculator in contagious currency crises: a single « George Soros » makes countries more vulnerable to crises, but mitigates contagion, Department of Economics, University of Wisconsin-Madison.

\section{Copyright Disclaimer}

Copyright reserved by the author(s).

This article is an open-access article distributed under the terms and conditions of the Creative Commons Attribution license (http://creativecommons.org/licenses/by/3.0/). 